\title{
A 52-year-old HIV-positive man with abdominal pain
}

\author{
Tashfeen Mehmood MD ${ }^{1}$, Matt J Chua MD², Faisal A Khasawneh MD³
}

\section{CASE PRESENTATION}

A 52-year-old African American man with untreated AIDS and active intravenous drug abuse presented with a three-day history of bilateral upper abdominal pain radiating to the back, which was associated with loss of appetite and generalized weakness. There was no fever or night sweats, and no vomiting, diarrhea, dysuria or hematuria. He denied cough, shortness of breath or chest pain. He also denied nasal congestion or headache.

Physical examination showed a cachectic middle-age man. Vital signs included temperature of $98.4^{\circ} \mathrm{F}\left(36.9^{\circ} \mathrm{C}\right)$, blood pressure $123 / 76 \mathrm{mmHg}$, heart rate 83 beats/min and a respiratory rate of 18 breaths/min. His lungs were clear to auscultation and his heart examination revealed normal heart sounds with no murmurs or gallops. Abdominal palpation revealed tenderness in the right upper quadrant and right costovertebral angle. $\mathrm{He}$ exhibited no rashes or lymphadenopathy.

Laboratory results revealed a white blood cell count of $3.3 \times 10^{9} / \mathrm{L}$ with absolute neutrophil count of $2 \times 10^{9} / \mathrm{L}$ and hemoglobin level of $96 \mathrm{~g} / \mathrm{L}$. The patient's CD4 cell count was 20 cells/ $\mu \mathrm{L}$ and HIV viral load was $>10^{5}$ copies $/ \mathrm{mL}$. Urine showed pyuria and a high leukocyte esterase level, but no hematuria. His serum creatinine level was $106.08 \mu \mathrm{mol} / \mathrm{L}$. The patient was started empirically on meropenem, but his symptoms persisted. A transthoracic echocardiogram showed normal ejection fraction and no valvular abnormalities or vegetations. Urine and blood cultures were negative. A computed tomography (CT) scan (Figure 1) and CT-guided biopsy were performed (Figure 2).

What is your diagnosis?

\section{DIAGNOSIS}

The CT scan of the abdomen identified a mass in the lower pole of the left kidney. The patient underwent a CT-guided biopsy, and histopathological examination revealed acute and chronic pyelonephritis with necrosis and invasive fungal hyphae demonstrating septation with dichotomous branching, consistent with Aspergillus infection (Figure 2). The culture grew Aspergillus fumigatus. CT scans of the chest and sinuses were within normal limits. The patient refused surgery; thus, he was discharged home on oral voriconazole $(4 \mathrm{mg} / \mathrm{kg}$ every $12 \mathrm{~h}$; serum drug levels were not monitored). However, his symptoms persisted, requiring readmission after nine weeks. He underwent left-sided nephrectomy (Figure 3) and was subsequently discharged on oral voriconazole. Unfortunately, his condition deteriorated over the next several months and he succumbed to AIDS.

\section{DISCUSSION}

The fungus Aspergillus is acquired by inhalation of airborne spores, which are abundant in indoor and outdoor environments $(1,2)$. On rare occasions, the spores may be inoculated through the skin and subsequently disseminate to the lungs, brain and other organs (2).

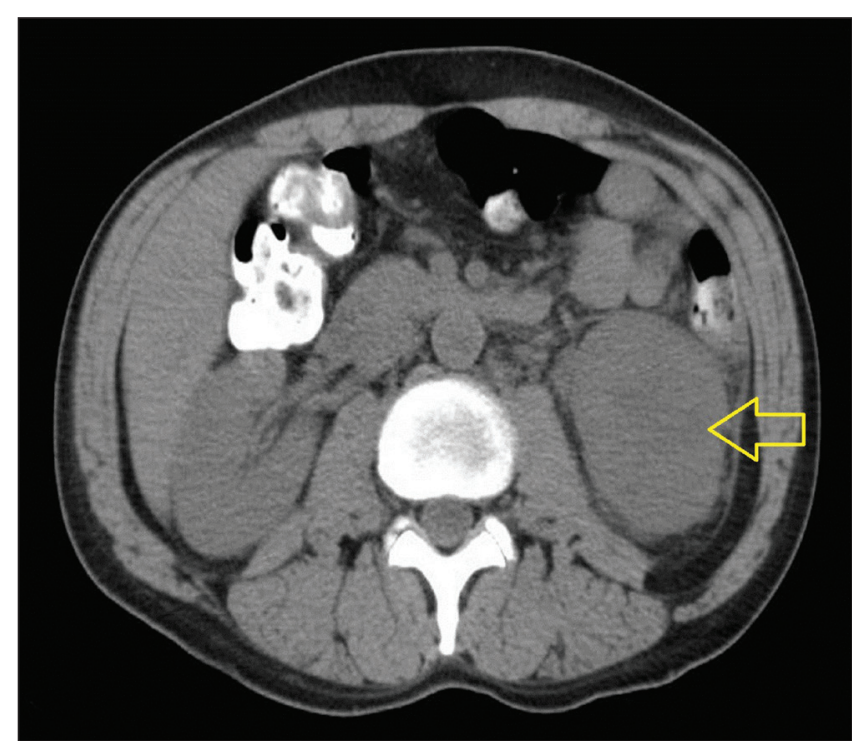

Figure 1) Computed tomography scan of the abdomen showing left renal mass (arrow)

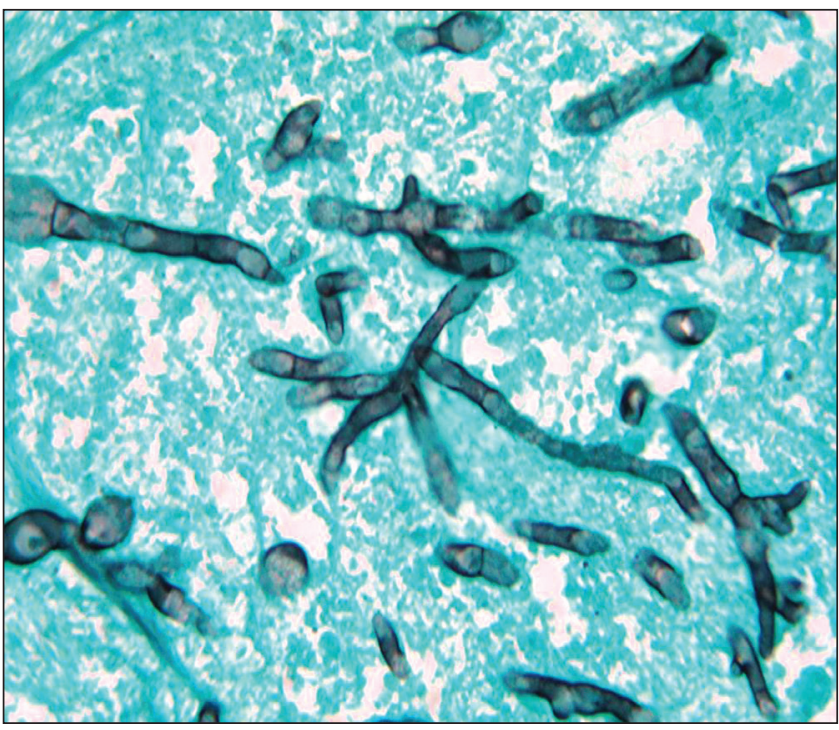

Figure 2) Gomori methamine silver stain showing septate fungal hyphae with dichotomous branching. Original magnification $\times 400$

'Section of Pulmonary and Critical Care Medicine, Department of Internal Medicine, Texas Tech University Health Sciences Center, Lubbock, Texas; ${ }^{2}$ Section of Cardiology, Department of Internal Medicine, Virginia Tech Carilion School of Medicine, Roanoke, Virginia; ${ }^{3}$ Section of Infectious Diseases, Department of Internal Medicine, Texas Tech University Health Sciences Center, Amarillo, Texas, USA

Correspondence: Dr Faisal A Khasawneh, Section of Infectious Diseases, Department of Internal of Medicine, Texas Tech University Health Sciences Center, 1400 South Coulter Street, Amarillo, Texas 79106, USA. Telephone 806-354-5480, fax 806-354-5765,

e-mail faisal.khasawneh@ttuhsc.edu 


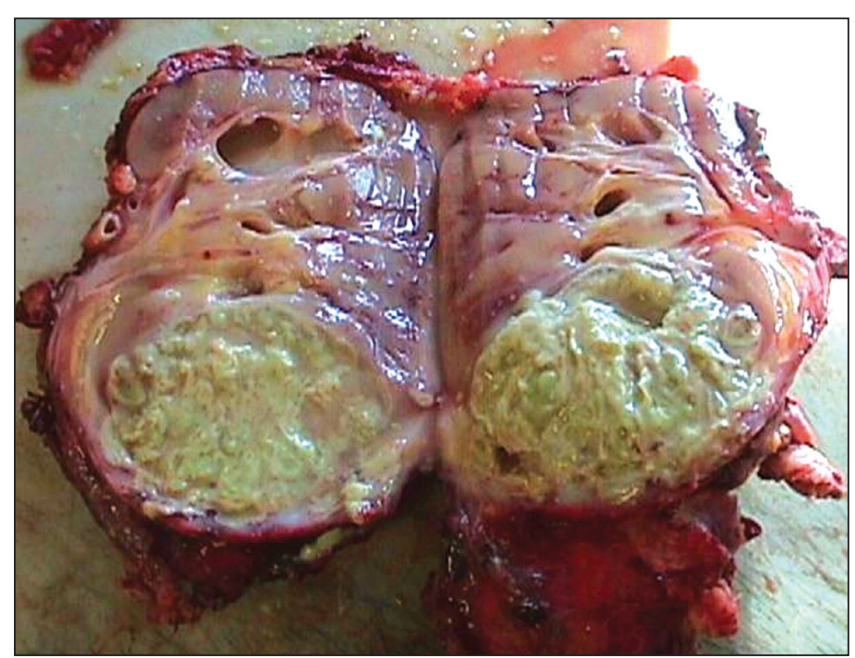

Figure 3) Gross specimen of left renal aspergilloma

Alveolar macrophages and circulating neutrophils prevent these conidia from invading the host tissues. In patients with impaired immunity (classically, individuals with prolonged neutropenia, hematological malignancies, advanced HIV infection, organ transplantation, intravenous drug abuse, chronic granulomatous disease and individuals on lengthy courses of high-dose corticosteroids and chemotherapy), the spores germinate into hyphae and a lifethreatening fungal infection may develop $(1,2)$. Recently, Aspergillus has been increasingly recognized as a potential pathogen in other patient populations such as critically ill patients and patients with chronic obstructive pulmonary disease $(3,4)$.

The development of aspergillosis depends on the number and virulence of inoculated organisms, as well as the immune status of the host. Aspergillus preferentially infects the lungs and sinuses but, in rare cases, can disseminate to other organs including the brain and kidneys. The clinical spectrum of disease ranges from a saprophytic infection such as aspergilloma, which develops in a pre-existing lung cavity, to an allergic disease such as allergic bronchopulmonary aspergillosis, or invasive infection such as invasive pulmonary aspergillosis.

Isolated renal aspergilloma is a rare complication of advanced AIDS. The largest case series to date reported 19 HIV patients with renal aspergilloma, 15 of whom exhibited unilateral aspergilloma (5). The mean age of the cohort was 38 years (range 26 to 48 years), and the most common reported risk factors were low CD4 count (average CD4 count was $<100$ cells/ $/ \mu \mathrm{L}$ ), neutropenia and steroid use. Of the 19 patients, seven (39\%) died. In this series, most Aspergillus infections occurred in the setting of multiple opportunistic infections. Previous episodes of pneumonia due to Streptococcus pneumoniae and other opportunistic infections, such as Pneumocystis jiroveci, cytomegalovirus and mycobacteria, are risk factors for pulmonary aspergillosis in patients with advanced HIV (6-8).

The rarity of Aspergillus infections in HIV patients is likely related to the preserved function of phagocytes until the advanced stages of AIDS. More than one-half of patients with AIDS who develop aspergillosis have either neutropenia secondary to ganciclovir or corticosteroid treatment as additional risk factors (8). Nevertheless, some HIV patients with aspergillosis have no other risk factors; this observation, combined with the fact that aspergillosis typically occurs in the setting of advanced HIV infection with a CD4 count $<50$ cells/ $/ \mu \mathrm{L}$, indicates that advanced HIV infection alone may represent an independent risk factor for invasive aspergillosis $(8,9)$. Renal involvement in patients with invasive aspergillosis may be underdiagnosed; Young et al (10) found renal involvement at autopsy in 20 of 98 patients with aspergillosis.

Clinical features of renal aspergillosis are nonspecific and include fever that does not respond to broad-spectrum antibiotics, abdomen and flank pain, and weight loss. Rarely, ureteral obstruction caused by Aspergillus bezoars has been reported (11). Early recognition of this lethal condition relies on a high index of suspicion that is based on patient risk factors and presentation, followed by appropriate imaging, preferably CT scanning. Definite diagnosis, however, hinges on obtaining appropriate tissue samples for culture and histopathological identification.

The ability to detect Aspergillus antigens (ie, galactomannan [GM] and beta-D-glucan) in serum and body fluids has improved our ability to diagnose this infection $(12,13)$. Unfortunately, their sensitivity and specificity continues to be modest at best. GM can be positive in other invasive mycoses. It can be falsely positive in patients taking piperacillin/ tazobactam and falsely negative in patients who have already been started on voriconazole $(14,15)$. It is worth mentioning that the currently available brand of piperacillin/tazobactam preparations is less likely to cause false-positive GM results (16). Furthermore, detecting Aspergillus nuclear material via polymerase chain reaction testing on serum, body fluids or tissue has been another development in the field and is currently undergoing rigorous testing (17).

Voriconazole is the drug of choice for treating aspergillosis (18). Lipid formulations of amphotericin B and echinocandins are considered to be alternative or adjunctive therapies. Recently, microwave ablation of aspergilloma has been successfully used in a patient with multiple comorbidities who was at a high risk for surgery (19). Despite current antifungal therapy alone or in combination with nephrectomy, renal aspergilloma continues to carry a poor prognosis, with a median survival time of three months.

\section{ACKNOWLEDGEMENTS: None.}

\section{FINANCIAL SUPPORT: None.}

DISCLOSURES: The authors have no conflicts of interest to declare.

\section{REFERENCES}

1. Segal BH, Walsh TJ. Current approaches to diagnosis and treatment of invasive aspergillosis. Am J Respir Crit Care Med 2006;173:707-17.

2. Kousha M, Tadi R, Soubani AO. Pulmonary aspergillosis: A clinical review. Eur Respir Rev 2011;20:156-74.

3. Samarakoon P, Soubani AO. Invasive pulmonary aspergillosis in patients with COPD: A report of five cases and systematic review of the literature. Chron Respir Dis 2008;5:19-27.

4. Khasawneh F, Mohamad T, Moughrabieh MK, Lai Z, Ager J, Soubani AO. Isolation of Aspergillus in critically ill patients: A potential marker of poor outcome. J Crit Care 2006;21:322-7.

5. Oosten AW, Sprenger HG, van Leeuwen JT, Meessen NE, van Assen S. Bilateral renal aspergillosis in a patient with AIDS: A case report and review of reported cases. AIDS Patient Care STDS 2008;22:1-6.

6. Miller WT Jr, Sais GJ, Frank I, Gefter WB, Aronchick JM, Miller WT. Pulmonary aspergillosis in patients with AIDS. Clinical and radiographic correlations. Chest 1994;105:37-44.

7. Khoo SH, Denning DW. Invasive aspergillosis in patients with AIDS. Clin Infect Dis 1994;19(Suppl 1):S41-8.

8. Holding KJ, Dworkin MS, Wan PC, et al. Aspergillosis among people infected with human immunodeficiency virus: Incidence and survival. Adult and Adolescent Spectrum of HIV Disease Project. Clin Infect Dis 2000;31:1253-7.

9. Lortholary O, Meyohas MC, Dupont B, et al. Invasive aspergillosis in patients with acquired immunodeficiency syndrome: Report of 33 cases. French Cooperative Study Group on Aspergillosis in AIDS. Am J Med 1993;95:177-87.

10. Young RC, Bennet JE, Vogel CL, Carbone PP, DeVita VT. Aspergillosis. The spectrum of the disease in 98 patients. Medicine (Baltimore) 1970;49:147-73.

11. Vuruskan H, Ersoy A, Girgin NK, et al. An unusual cause of ureteral obstruction in a renal transplant recipient: Ureteric aspergilloma. Transplant Proc 2005;37:2115-7.

12. Pfeiffer CD, Fine JP, Safdar N. Diagnosis of invasive aspergillosis using a galactomannan assay: A meta-analysis. Clin Infect Dis 2006;42:1417-27.

13. De Vlieger G, Lagrou K, Maertens J, Verbeken E, Meersseman W, Van Wijngaerden E. Beta-D-glucan detection as a diagnostic test for 
invasive aspergillosis in immunocompromised critically ill patients with symptoms of respiratory infection: An autopsy-based study. J Clin Microbiol 2011;49:3783-7.

14. Mennink-Kersten MA, Donnelly JP, Verweij PE. Detection of circulating galactomannan for the diagnosis and management of invasive aspergillosis. Lancet Infect Dis 2004;4:349-57.

15. Marr KA, Laverdiere M, Gugel A, et al. Antifungal therapy decreases sensitivity of the Aspergillus galactomannan enzyme immunoassay. Clin Infect Dis 2005:40:1762-9.

16. Mikulska M, Furfaro E, Del-Bono V, et al. Piperacillin/tazobactam $\left(\right.$ Tazocin $^{\mathrm{TM}}$ ) seems to be no longer responsible for false-positive results of the galactomannan assay. J Antimicrob Chemother 2012;67:1746-8.
17. Hizel K, Kokturk N, Kalkanci A, Ozturk C, Kustimur S, Tufan M. Polymerase chain reaction in the diagnosis of invasive aspergillosis. Mycoses 2004:47:338-42.

18. Walsh TJ, Anaissie EJ, Denning DW, et al; Infectious Diseases Society of America. Treatment of aspergillosis: Clinical practice guidelines of the Infectious Diseases Society of America. Clin Infect Dis 2008;46:327-60.

19. Waller S, Raglow Z, Lemons S, et al. Microwave ablation of a large renal aspergilloma. Transpl Infect Dis 2014:16:496-500. 


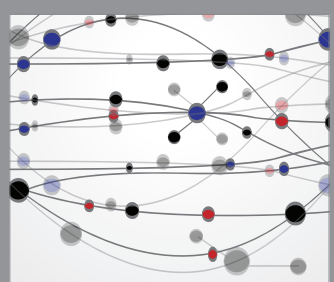

The Scientific World Journal
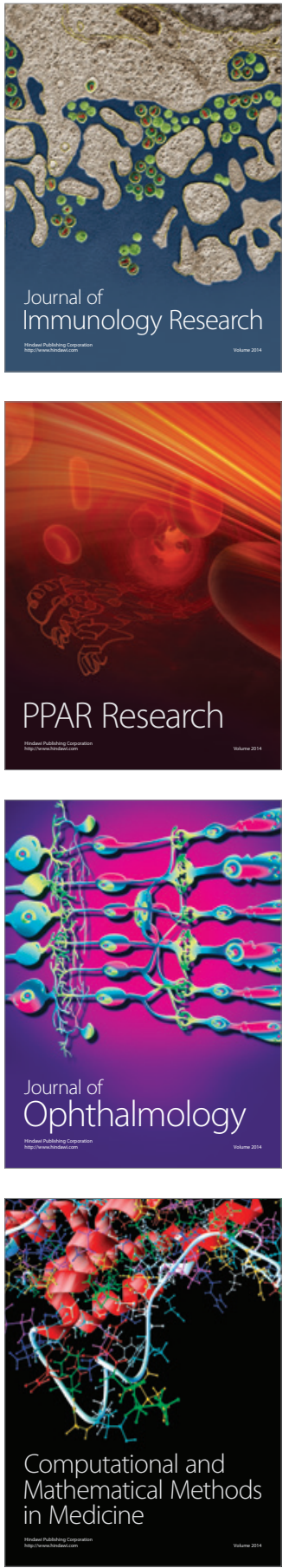

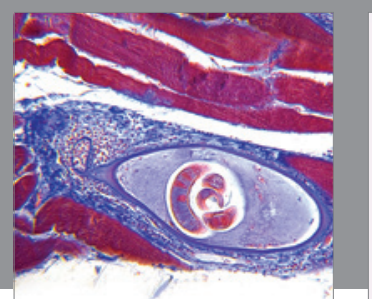

Gastroenterology Research and Practice

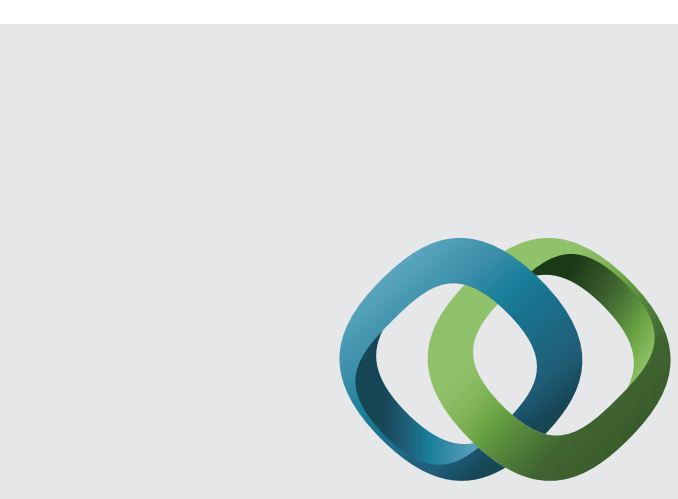

\section{Hindawi}

Submit your manuscripts at

http://www.hindawi.com
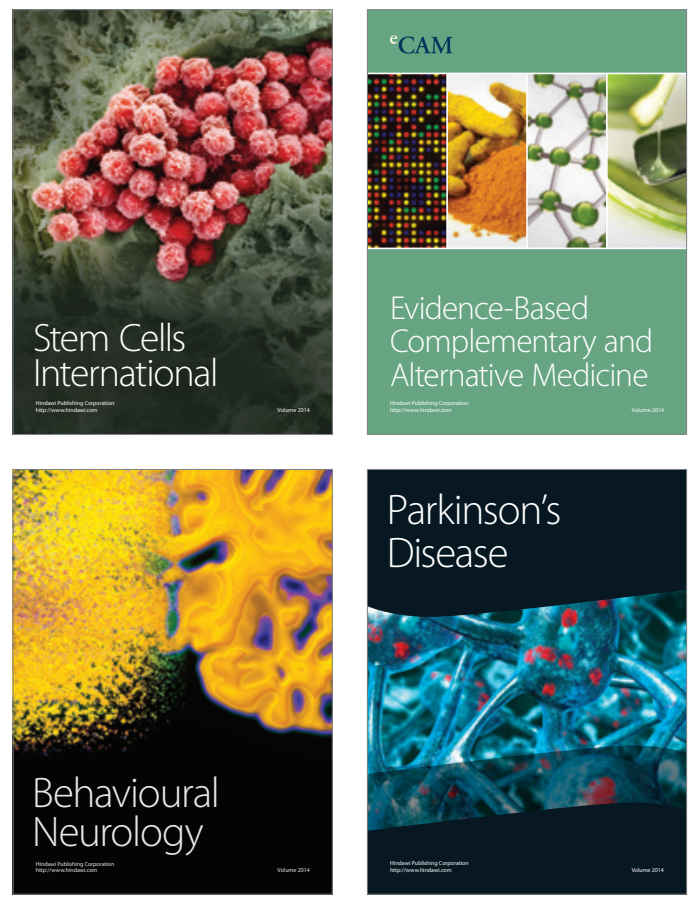
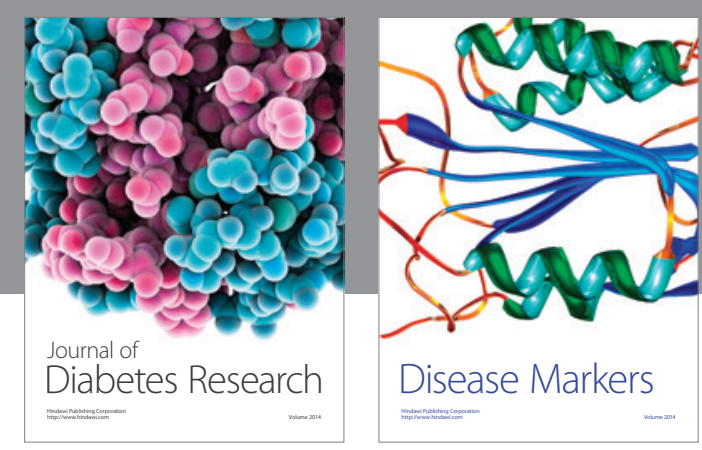

Disease Markers
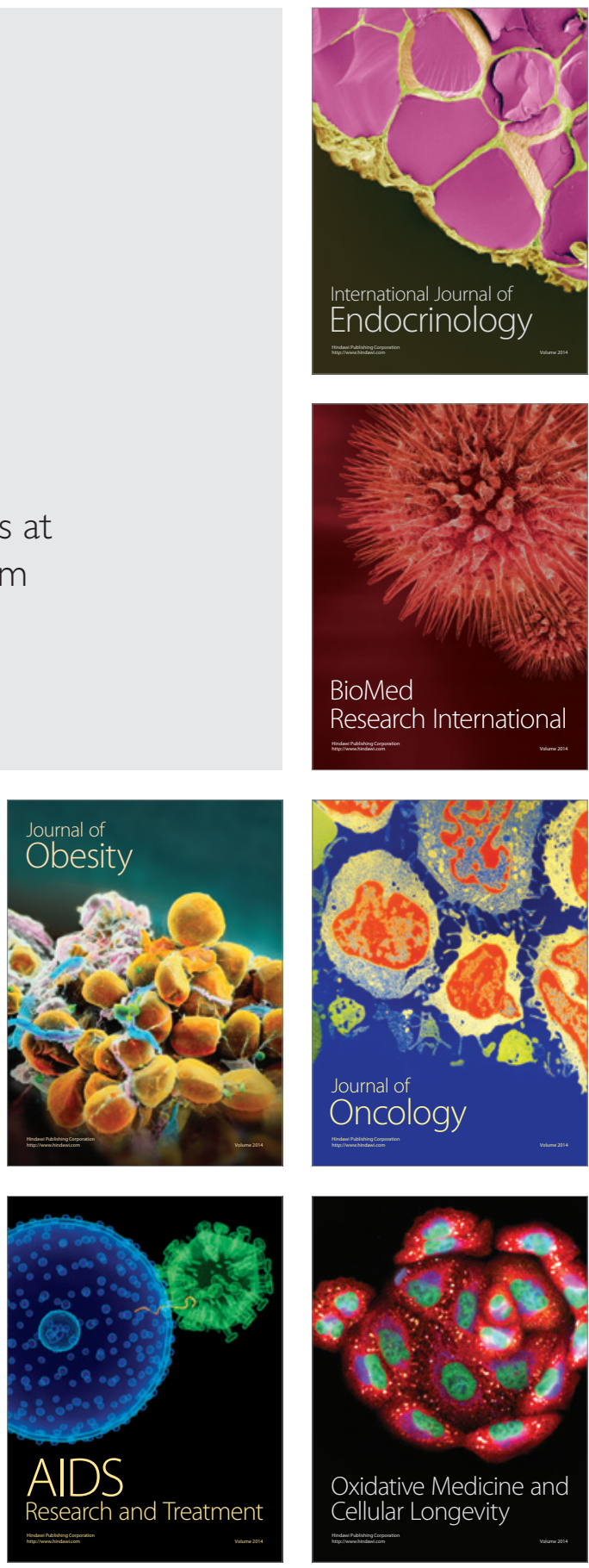